\title{
Das redes de pesca às redes da imaginação criadora - Novos elementos para uma epistemologia da comunicação \\ Cláudio Paiva*
}

\begin{abstract}
RESUMO
No texto buscou-se pensar a "cultura das redes" como uma metáfora pertinente para traduzir o sentido das experiencias de sociabilidade e comunicabilidade no contexto brasileiro, cujos tempos de trabalho e de lazer estão profundamente ligados a uma semântica e uma pragmática das "redes". No contexto da aceleração tecnológica do século XXI, os recentes processos multimidiáticos (abrangendo as midias analógicas e digitais) configuram uma experiência cultural hibrida em que as formas pré-industriais e pós-modernas se encontram (e se confrontam). A idéia é pensar uma epistemologia dialógica e sensivel que possa dar conta dessa complexidade cultural
\end{abstract}

\section{ABSTRACT}

The article discusses the concept of "network culture" as an useful metaphor to analize the experiences of sociability and communicativeness in Brazilian society, whose times of work and leisure are deeply linked to a "network" semantic and pragmatics. In the context of technological acceleration of the 21 th century, the recent multimediatic processes (including both the analogical and digital media) create a hibrid cultural experience, in which pre-industrial and post-modern face and confront each other. The article proposes a dialogic and sensible epistcmology to give account of this cultural complexity.

\footnotetext{
*Pho em Sociologia . Universidade de Paris $V$ e professor do Departamento de Comunicação da UFPB.
} 


\section{Introdução}

A "cultura das redes" aparece aqui como uma metáfora pertinente para traduzir o sentido das experiências de sociabilidade e comunicabilidade no contexto brasileiro, cujos tempos de trabalho e de lazer têm se realizado visceralmente ligados a uma semântica e uma pragmática das "redes", sejam "redes de dormir", "redes de pescar" ou redes de informação. No contexto da aceleração tecnológica do século XXI, a configuração das redes como instância do trabalho ao ar livre, como instância do repouso, do sonho e do devaneio poético aparece como uma circunstância que não pode ser negligenciada no trabalho de leitura e interpretação da cultura porque traduz experiências reais, cuja força imaginante e concretude histórica ocupam os mesmos espaços e tempos que estruturam as novas redes informacionais.

O controle remoto, o computador, o fax, a Internet, os vídeo-games, os celulares etc geraram novas experiências culturais, inclusive, as inovações no âmbito dos discursos e das práticas comunicacionais. $\mathrm{O}$ ensino à distância, as teleconferências, o namoro virtual, a correspondência on line, a virtualidade dos textos on line etc criaram novas espacialidades e temporalidades. A aceleração e ubiqüidade dos fluxos de comunicaçã̀o atualizaram para o sentido da "cultura das redes". Ocorreram alterações fundamentais nos tempos do trabalho e nos tempo do lazer, simultaneamente houve mutações nos modos de socialização entre os indivíduos e grupos.

Os recentes processos multimidiáticos (abrangendo as mídias analógicas e digitais) configuram uma experiência cultural híbrida em que as formas préindustriais e pós-modernas se encontram (e se confrontam). Estas novas empiricidades, conseqüentemente, exigem o refinamento de uma epistemologia dialógica e sensível que possa dar conta da complexidade cultural.

Numa mesma cartografia social se inscrevem as imagens, sons e letras das difusoras, rádio-portáteis e rádios digitais, cartas manuscritas, telegramas fonados e mensagens eletrônicas, festas folclóricas e megaproduções cinematográficas. O samba, o axé, o funk e as raves, em seus diferentes registros sonoros, rítmicos, desejantes e sensoriais repartem as atenções e preferências da juventude. Na chamada era da mundialização as fronteiras se tornaram mais próximas e isto implica uma dimensão de pureza, mas também de perigo. $\mathrm{Na}$ época dos mercados globais faz-se necessário distinguir as formas anômicas e salutares em que se misturam o tradicional e o ultramoderno.

Num mesmo espaço regional se inscrevem as enxadas e os computadores, as feiras tradicionais e os hipermercados, as receitas domésticas e a engenharia genética. Isto configura um quadro exuberante, barroco, multifacetado que solicita o rigor de um olhar mais atento e preparado.

$O$ desafio que se coloca então é interpretar a forma e o sentido das culturas híbridas (como a brasileira, que agrega tantas diferenças e disparidades) na 
era da informação. Convém explorar o modo como as novas tecnologias da informação e da comunicação se projetam nas estruturas do cotidiano, impulsionando novas formas de "inteligência coletiva", novos modos do "agir comunicacional", novas "competências comunicativas" e novos estilos de intersubjetividade. Numa palavra, perseguimos as pistas que nos permitam compreender as formas possiveis de superação do atraso, denunciando os tipos de exclusão e ultrapassando os niveis de regressão, porém apostando num estilo de emancipação da experiência cultural, nos caminhos para o desenvolvimento e na participação dos indivíduos nas decisões públicas.

\section{Gestão da felicidade na cultura das redes}

A nossa argumentação acerca da comunicação e cultura no Brasil pretende colocar em perspectiva o problema das novas tecnologias, tentando acertar os ponteiros com os novos discursos institucionais e instituintes movidos pela irradiação da idéia do "novo". Após a eleição no Brasil de um Presidente da República advindo dos estratos mais populares, irradia-se uma aura de novidade e esperança, e de certo modo, isto implica na renovação das apostas acerca do tema do desenvolvimento sustentável. Assim, situamos o debate sobre as tecnologias de comunicação geradoras de uma atualização na "cultura das redes", considerando a "coincidência dos opostos" que reúne num mesmo intervalo histórico as formas tradicionais e ultramodernas. Isto é, verificamos a nova ambiência cultural por um prisma que considera as configurações econômicas, sociais, políticas e culturais antigas e as mais recentes.

Situamos um lugar de fala no contexto de uma antropologia da comunicação, considerando os processos comunicacionais em sua relação com o mundo do trabalho, vida e linguagem. Assim, lançamos um olhar sobre os modos como os atores sociais realizam suas experiências profissionais por meio das tecnologias da informação e da comunicação (NTIC), como os internautas partilham as emoções, afetos e sensações através da Internet, e como as novas linguagens produzidas, postas em circulação e consumidas pelos usuários se irradiam no cotidiano gerando novas produções de sentido, estilos de comunicabilidade e de sociabilidade. Exploramos as mutações nas formas cognitivas, socializantes, sensoriais, estéticas e politizantes que se instauram no espaço das redes de virtualidade. E buscamos examinar como as NTIC se processam junto aos processos sócio-históricos e entendemos que tudo isso solicita uma investigação mais detida.

Mas para isso permanecemos atentos às formas históricas, sociais e subjetivas, às concretudes e empiricidades que formalizam o espectro da cultura das redes. Ou seja, procuramos decifrar os tipos de relações dialógicas, simultâneas e interativas entre os seres e as técnicas que habitam cada um dos novos meios de informação e de comunicação. Desta maneira, buscamos 
apreender os modos de pensar, dizer, saber, poder e agir que os atores sociais desenvolvem no contato imediato com as máquinas de comunicar.

Os novos estilos de vida marcados pelo hibridismo de formatos e tendências expressam uma estilística da existência guarnecida por diferentes registros territoriais, cronológicos, sensoriais, políticos e ecológicos. As metrópoles sonham o sonho de felicidade num cotidiano arborizado pelos shoppings, arranha-céus, estacionamentos gigantes, hipermercados e aeroportos eficientes. Isto é quase tão natural quanto ao fato dos "andróides sonharem com ovelhas elétricas". Essa dimensão do imaginário pós-moderno não está ausente do cotidiano do Brasil no século XXI. Depois da proliferação das mídias assistimos a uma mundialização das imagens de maneira que ninguém, mesmo nas regiões mais remotas, está imune às irradiações globais. Isto implica na difusão, circulação e consumo de imagens, sons, letras, cifras e símbolos que contaminam o planeta. Mas é interessante observar que esta "irradiação global" também leva à difusão das culturas locais para o espaço global, com toda a sua rede de desejos e representações, afetos, emoções, sentimentos, utopias e paixões.

Vivenciamos uma era em que proliferam os diagnósticos sobre a exacerbação do individualismo, narcisismo e massificação. $\mathrm{Na}$ época dos mercados globalizados os paraísos artificiais também fulguram como "aparências de felicidade" na periferia do capitalismo global. Aqui, ressoam os ecos de posturas afirmativas que reconhecem a positividade dos novos 158 estilos de comportamento numa sociedade em que os indivíduos e grupos reinventam as suas "ilusões necessárias", recriam as modalidades de atração e de trocas coletivas, refazem as utopias e os milagres driblando as formas recessivas e injustas do cotidiano.

Enquanto isso, nos domínios da economia, política, vida social, artes e ofícios do cotidiano os indivíduos não cessam de se reterritorializar. Os seres em redes de solidariedade dedicam-se permanentemente a refazer os modos de expressão de suas intersubjetividades. No exercício ativo das tramas culturais os homens em tribo atualizam a memória, a tradição e a história de suas vidas cotidianas em meios às novas interfaces urbanas, industriais, tecnológicas e cibernéticas que os assediam e os fascinam, que lhes atrapalham o percurso, mas também lhes abrem novos caminhos. Os novos dispositivos podem gerar desemprego, mas também podem abrir novas frentes de trabalho; podem propiciar migrações sofridas, mas podem despertar para outras percepções, afetos e sociabilidades felizes.

As culturas híbridas encerram contradições e os paradoxos, mas ao mesmo tempo, abrangem as dimensões que incluem - positivamente - a "coincidência dos opostos" de forma efervescente e vitalista. Experimentamos em nossa pós-modernidade inúmeros desafios expressos pela pluridiversidade de mundos que às vezes parecem irreconciliáveis. $E$ de fato existe uma série de 
tensões na interpenetrabilidade destes mundos dotados de características bem diferentes. Ontem isto se fazia presente pela disparidade entre a modernidade urbano-industrial e o atraso sócio-econômico. Hoje as desigualdades se mostram atualizadas sob uma nova espécie de apartheid cultural. Ou seja, de um lado temos a configuração de redes em que os indivíduos e grupos sociais estão interconectados através dos satélites, das parabólicas e das tevês pagas. Do outro lado, temos a permanência de outras tribos formadas pelos televidentes ligados na programação das tevês abertas, cuja programação se faz de maneira massiva. Além disso, há os novos outsiders da sociedade da informação on line, compondo a tribo dos "sem micro", o que, de certo modo, remete à situação dos sem-terra. Contudo, esta conjuntura atual demanda astúcia, reinvenção e a adoção de estratégias eficientes que possam transformar as crises em oportunidades.

Estes fatos levam a uma reflexão que não pode deixar de considerar a dimensão dos abismos sócio-econômicos, políticos e culturais do Brasil. E no caso do nordeste brasileiro, particularmente, isto se mostra em toda a sua evidência, considerando-se que esta região representa o espaço geoeconômico e geopolítico mais desnivelado no âmbito da federação.

No que concerne especificamente à atualidade da cultura das redes, verificamos que o problema remete à comunicabilidade e particularmente à questão do acesso à informação, à educação e às diversas modalidades culturais que poderiam balancear o desnivelamento dos fluxos informacionais e comunicacionais. Assim, no contexto das culturas híbridas do Brasil (e do Nordeste), o desafio que se impõe é mapear as formas culturais e sociais que se delineiam no contexto do nordeste brasileiro, num intersticio dos espaços e tempos inteiramente atravessados pelos processos midiáticos. Sendo uma região que experimenta distintas espacialidades e temporalidades, ou seja, contendo traços da idade média, moderna e pós-moderna - o nordeste permanece um enigma. Primeiramente porque há cinco séculos resiste às diferentes formas de assédio e padronização, exibindo uma fisionomia particular dentre as outras regiões do Brasil; depois porque conserva um repertório de expressões artisticas e culturais que sendo extemporâneas, adeqüam-se bem numa tradução das culturas híbridas do planeta, constituídas pelos nãolugares e temporalidades imprecisas, onde se misturam o arcaico e o ultramoderno; e finalmente, pelo sincretismo das festas religiosas e seculares, imagens sagradas e pagãs que terminam por imprimir um espírito profundamente trágico à cultura, conduzindo os indivíduos a se portarem afirmativamente face às intempéries do destino e da vida dura.

Procurando transcender os espectros de crise e espreitar a emergência de novas oportunidades, permanecemos "de olho nas frestas" de um sistema econômico-politico global que se mostra bastante excludente, mas que permanentemente contém as chaves para decifrarmos o enigma das formas 
de segregação social, econômica, política (e comunicacional). Apostamos ser possível nos instalarmos no interior deste "sistema" e apontar as estratégias de comunicação que podem contribuir para a reversão do quadro global de adversidades. Para isso, recorremos às ferramentas teóricoconceituais do campo das Ciências da Comunicação (e suas interfaces com as ciências humanas e sociais), um campo que há mais de meio século não tem cessado de reinventar os seus métodos de análise e seus modos de intervenção na tramas sócio-culturais.

\section{Novas competências na iniciação e capacitação científica}

Gostaríamos aqui de enumerar algumas experiências que tivemos a chance de vivenciar no âmbito do ensino e pesquisa no Departamento de Comunicação, da UFPB. Isto nos parece pertinente primeiro para mostrar as articulações que se fazem entre o trabalho de fundamentação científica e as práticas laboratoriais gerando aptidões e habilidades num contexto profissional que passo a passo vem atualizando as suas práticas, otimizando os recursos humanos e tecnológicos.

\section{a) A busca da comunicação horizontal}

A primeira oportunidade que tivemos de nos aproximar de um estudo da cibercultura data mais ou menos de uma década. Orientamos os trabalhos de

160 Iniciação Científica - PIBIC, de duas alunas interessadas no tema do ciberespaço, intitulado "A busca da comunicação horizontal" (Patrícia e Aline).

De maneira inteligente elas partiram da vontade de estudar as páginas eletrônicas da Internet, examinando o agenciamento de novas competências no campo da comunicação. Dedicaram-se à região Nordeste - particularmente ao Estado da Paraíba - e partiram das idéias propostas por Luiz Beltrão, contidas num texto claro e pedagógico, chamado "Adeus Aristóteles: o fim da comunicação vertical" [--]. Mas como de praxe em estudos desta natureza, o enfoque que se apoiara numa base crítica, terminou se desenvolvendo por um caminho mais funcionalista. Descreveram uma certa quantidade de sites, observando sua eficácia e utilidade. Investigaram estatisticamente o número de provedores no Estado, sem deixar de cuidar do aspecto qualitativo dos sites. Realizaram uma boa análise de conteúdo, tratando de apontar para as funções e disfunções presentes na configuração das páginas. Observaram a qualidade técnica, os efeitos audiovisuais e cumpriram o protocolo de uma enquete sobre um novo meio partindo de um prisma tradicional nas academias norte-americanas. 


\section{b) Walter Benjamin e a imaginação cibernética}

Dali em diante o nosso interesse pela cibercultura cresceu e dedicamos ao assunto um artigo sob a rubrica "Walter Benjamin e a Imaginação Cibernética". A idéia geral era então fazer um mapeamento de "ocorrências" do mundo on line, examinando as suas significações no cotidiano e para isso, nos apoiamos em fragmentos, noções e conceitos presentes nos textos de Walter Benjamin. A nossa estratégia fora de revisitar a perspectiva de Benjamin acerca da modernidade, em sua coleta dos textos, imagens, objetos, figuras e personagens que a seu ver tinham animado o cenário da modernidade na passagem do século XIX ao século XX.

\section{c) Construção de um "Quiosque" interativo}

Participamos em seguida de uma banca examinadora, em que uma aluna se propunha a transformar uma revista imprensa para o formato digital. A revista "Quiosque", editada pelo professor Henrique Magalhães consiste numa revista de tamanho curto e de circulação limitada, mas que tem a qualidade de reunir artigos de estudantes, professores e pesquisadores em comunicação e assuntos afins. A transcodificação me pareceu exitosa porque em primeiro lugar, a aluna manteve a leveza gráfica característica da "Quiosque" em seu formato original. Depois pela otimização dos recursos que permitiriam uma certa agilidade na busca dos textos. E finalmente, pela disponibilização em rede de um produto de qualidade, mas que até então se mantivera restrito às consultas de um número reduzido de leitores, na faculdade de comunicação da Paraíba.

O número de usuários dos computadores dentre os alunos de comunicação da UFPB ainda se mostra um tanto incipiente. Entretanto a cada dia mais e mais alunos engrossam as fileiras dos interessados pelo tema da cibercultura.

\section{d) Webdifusão: radio digital - do local ao mundial}

Uma experiência interessante se deu com uma turma de quatro concluintes do curso que me convidaram para compor a sua banca. Eles tinham as suas atenções voltadas para o sistema de webdifusão, ou seja, as rádios digitais e se incumbiram de produzir um "programa de rádio" a ser disponibilizado en rede. Para isto contaram com a orientação eficiente do Prof. Carmélio Reynaldo. Superando as dificuldades materiais (linhas telefônicas defeituosas, conexões lentas e limitações dos aparelhos já ultrapassados), os alunos conseguiram realizar um trabalho bastante interessante. Dentro de um contexto minado pelas adversidades orçamentárias, pela redução de investimentos, falta de uma bibliografia especializada e mesmo uma certa escassez de recursos humanos para trabalhar com suportes mais arrojados, eles colocaram no ar a primeira rádio digital do Departamento de Comunicação da UFPB. 
Assim, estas primeiras experiências com a "comunicação em rede" foram marcadas pelo cuidado com os aspectos técnico-instrumentais, com a operacionalidade dos sistemas inteligentes, enfim, com a dimensão mais infraestrutural e performativa das mídias digitais.

\section{e) Tecnologia e afetividade das relações virtuais}

No comecinho do novo século a aluna Juliana Carmem Rodrigues nos procurou buscando orientação para o seu projeto de conclusão de curso, tratando das "relações virtuais", num projeto que terminou ganhando um belo título: "Comunicação, Sentimento e Interatividade: Um estudo das relações afetivas nas salas de bate-papo da Internet".

Diferentemente da maior parte das investigações sobre o bate-papo na Internet, Juliana Rodrigues preteriu o "discurso da sexualidade" e optou por uma análise do discurso da afetividade, visando as relações de amizade no espaço efêmero das salas de bate-papo. Aqui teríamos um primeiro deslocamento, deixando de lado o aspecto material, infra-estrutural, técnicoinstrumental que tem norteado o interesse da maior parte das pesquisas na graduação. A nova postura da pesquisadora movia-se pela intenção de analisar os discursos, examinar as suas condições de possibilidade, a sua produção de sentido. Então ela tinha aliado as preocupações das ciências sociais, dos estudos culturais e das ciências da linguagem, dirigindo-se para as proximidades da análise dos discursos. Ali, o quantitativo cedera lugar ao qualitativo. No contexto da mundialização das trocas simbólicas, Rodrigues construiu um histórico, apontando para o correio sentimental da comunicação epistolar (recorrendo às correspondências dos namorados virtuais através de cartas) e para as experiências telefônicas do "Disque Amizade", como uma pré-história das relações afetivas na Internet. Estavam lançadas a preliminares para os estudos de comunicação orientados por uma perspectiva históricohermenêutica, em que a opinião e a mera informação empírica cediam terreno para as práticas interpretativas.

\section{f) Experimentações e competências do novo milênio}

Certamente uma das elaborações mais arrojadas produzidas no âmbito dos trabalhos de conclusão de curso, sob a rubrica dos Projetos Experimentais, foi apresentada pelo aluno Vinícius de Oliveira, que ousou realizar a primeira defesa de monografia para obtenção do grau de bacharel em comunicação em conexão com a Internet. Em tempo real os alunos e interessados puderam assistir e interagir com o pesquisador durante o momento de sua apresentação. Assim, transformando a crise em oportunidade tivemos ali o exemplo de uma estratégia feliz que soube aliar competência técnica e imaginação criadora tratando de um tema relevante, pois debruçou- 
se sobre a disponibilidade virtual dos jornais locais no Estado da Paraiba. (título da monografia: Ensino de Jornalismo em Rede).

Oliveira é responsável pela formatação de um Centro de Informação On Line (CIO), uma experiência pioneira no mundo da telemática produzida por um aluno de comunicação da UFPB. Trata-se de um site contendo inovações no campo da comunicação e ciências afins. Professores, pesquisadores, estudantes e especialistas encontram nesta página um meio eficaz de expor suas idéias, publicar seus textos, disponibilizar seus artigos. O CIO contém uns links conectando os usuários aos principais jornais e às páginas ligadas aos temas da comunicação, cultura e sociedade.

\section{g) Comunicação e cultura organizacional no ciberespaço}

Uma experiência igualmente curiosa se expressa no trabalho de Antonio Henrique Araújo, inscrito no programa de bolsas de iniciação cientifica, desde o ano 2002. O jovem pesquisador, matriculado na habilitação de Relações Públicas, do curso de Comunicação Social da UFPB, tem se dedicado a realizar um mapeamento seletivo dos sites das universidades, tratadas enquanto manifestações de "comunicação e cultura organizacional". Para isso, o mesmo tem se guarnecido de diversos textos teóricos, consolidando a sua fundamentação cientifica através de uma rigorosa revisão bibliográfica, além de repertoriar um acervo importante de textos na Internet, cujos conteúdos têm afinidade com o seu objeto de pesquisa. Tendo se voltado para a dimensão interativa dos meios de comunicação, Antonio Henrique Araújo tem vivenciado na prática os aspectos presentes em seu tema de estudo, na medida em que realiza simultaneamente uma experiência intermidiática, passando pelo registro das mídias analógicas até as mídias digitais.

Prestando assessoria para profissionais de webjornalismo, o pesquisador empenhou-se no trabalho de registrar num gravador os discursos radiofônicos de políticos, empresários, artistas, formadores de opinião e transcrevê-los para o texto digital. Por questões de detalhamento e agilidade, sua tarefa seria de decodificar, transcrever as falas gravadas para o texto manuscrito e isto freqüentemente era feito por meio de manuscritos com canetas esferográficas e papel de oficio. Dali em diante, o próximo passo seria digitar os textos num computador público e em seguida enviar o produto por email para o seu destinatário, que posteriormente se encarregaria de disponibilizar os textos na Internet, prontos para serem acessados pelos virtuais usuários.

O interessante neste percurso é o fato de se tratar de uma pesquisa que alia a experiência teórica e a dimensão pragmática do objeto de estudo. $\mathrm{O}$ aluno interessado em estudar a sociedade em rede, ao mesmo tempo em que consulta os trabalhos de Pierre Lévy, Castells e Mattelart, entre outros, além daqueles especializados nos assuntos de Relações Públicas e da Comunicação 
Organizacional. O mesmo pôde experimentar na prática o trânsito característico dos processos intermidiáticos, passando do rádio à escrita, da escrita ao computador à Internet. Este é um exemplo de trabalho que expressa com clareza a intervenção num processo de comunicação em rede. $O$ exercício da escuta, da escritura, comunicação digital, reticular e binária se fundem aqui num tipo de intertextualidade, intermediatização e intersemioticidade que revelam a nova forma e sentido da comunicação social - abrangendo as dimensões da vida, trabalho e linguagem.

h) A Webdifusão tem sido desenvolvida na UFPB também graças aos esforços do Prof. Carmélio Reynaldo (cursando atualmente a pós-graduação em Educação). Aliando a sua experiência de teleradiodifusão, as pesquisas sobre os movimentos sociais e a manutenção duradoura de um programa de rádio, Reynaldo tem contribuído para uma linha evolutiva no tocante aos estudos avançados dos audiovisuais.

i) O CEAD - Centro de Educação à Distância consiste num núcleo de produção tecnológica da UFPB que tem colocado a Universidade Federal da Paraiba no trânsito das infovias, gerando novas modalidades de produção, circulação e acesso ao conhecimento.

Estas são algumas experiências pontuais que nos serviram para contemplar os estágios de evolução no domínio das tecnologias de comunicação, suas interfaces com as práticas sócio-culturais e suas relações com a produção de conhecimento científico visando o desenvolvimento sustentável do nordeste. Entretanto aqui tratamos especificamente das atividades mais ligadas ao mundo acadêmico, à universidade $\mathrm{e}$ as suas conexões num nível mais local, interno, regional.

\section{Amantes e desconfiados nas tramas do virtual}

Discutimos aqui as relações entre comunicação, cultura e sociedade, enfatizando o contexto da região Nordeste. Portanto, naturalmente temos que passar pelo crivo do tema do "desenvolvimento sustentável". E o desafio que se impõe - em princípio - é superar os tons de ressentimento. Ao invés disso, conviria examinarmos os jogos de linguagem, as modalidades das estratégias encontradas pelos indivíduos e grupos, os tipos de acordos, negociações, subversões e adequações, numa palavra, o estilo da carnavalização empregada pelos atores sociais no trabalho de gerenciamento das informações, nos processos educacionais, nos regimes de comunicabilidade e de sociabilidade que animam o cotidiano.

Metodologicamente, apresentamos um breve itinerário das pesquisas sobre comunicação (com ênfase nos estudos de cibercultura), mostrando os 
encontros e confrontos das várias correntes teóricas; assim, no conjunto formado por diferentes teorias e metodologias, vislumbramos uma possibilidade de análise das experiências culturais e suas relações com os diferentes processos tecnológicos, midiáticos e comunicacionais.

Já tem sido uma praxe nos estudos das novas tecnologias de comunicação recorrer aos trabalhos de Pierre Lévy - que tem se revelado o grande especialista sobre o tema - e que tem dividido opiniões dentro e fora dos muros acadêmicos [1]. Para alguns of filósofo tem-se mostrado um eficiente pesquisador da cibercultura, gerando investigações fecundas e conseqüentes. Para outros, o seu fascínio pelas novas tecnologias tem obliterado questões importantes concernentes à economia, sociedade, cultura e política. Genericamente, percebemos que Lévy participa hoje de uma nova querela semelhante àquela que no passado recente, no que concerne à cultura de massa, colocou em pólos distintos autores como McLuhan [2] (visto como um "integrado") e autores como os frankfurtianos (particularmente Adorno e Horkheimer, vistos como "apocalípticos" diante dos meios de comunicação e da cultura de massa) [3]. Atualmente, a discussão dos novos meios tecnológicos e suas interfaces com o processo de informatização social, encontra os seus mais tórridos antagonistas nas figuras de Jean Baudrillard ("Tela Total, Mitoironias do virtual") [4] e Paul Virilio ("A Bomba Informática") [5].

Compartilhamos o ponto de vista que as disputas e discussões acadêmicas acerca das NTC têm sido férteis, principalmente na medida em que despertam a atenção dos jovens pesquisadores para as possibilidades de confrontos \& convergências sobre um tema como este ultra-relevante em nosso domínio. Compreendemos que este pode vir a se constituir num ponto de partida - até certo ponto saudável - para o debate, mas que é mais importante - por exemplo - situar a pertinência dos argumentos dos autores e a eficácia dos seus textos para apreciarmos a inserção das novas tecnologias de comunicação no contexto de uma sociedade em desenvolvimento como é o caso do Brasil (e especificamente do nordeste brasileiro).

Em nosso estudo da cultura das redes buscamos observar em que proporção as noções, metáforas, imagens e conceitos utilizados por pensadores como Lévy e Baudrillard podem agilizar um entendimento do modo como as novas "máquinas de comunicar" propiciam novos modos de pensar, dizer e agir, assim como podem instigar uma compreensão crítica das diferentes maneiras como os usuários, internautas e pesquisadores se apropriam das informações em rede tornando-se mais competentes em sua comunicação cotidiana. Interessam-nos os enfoques apologéticos e apocalípticos acerca dos meios digitais quando e se nos trouxerem novas luzes acerca do caráter regressivo e emancipatório da cultura das redes no contexto brasileiro e nordestino. 


\section{3) O poder das identidades na sociedade em rede do fim de milênio}

A obra do catalão Manuel Castells [6] "A Era da Informação: Economia, Sociedade e Cultura", em três grossos volumes, tem sido considerada uma empreitada de envergadura comparável ao trabalho de Max Weber "Economia e Sociedade" [7]. Ou seja, um marco divisor nos estudos da Economia e Sociedade do século XX. Os três volumes "A sociedade em rede", "O poder da identidade" e "Fim de Milênio" consistem num vasto material que, imbuído numa perspectiva crítica, empenha-se em decifrar o alcance e os limites, os paradoxos e as contradições, as especificidades e generalidades das redes de informação como produto mais acabado na nova fase do capitalismo global.

Em consonância com uma obra de peso como "Era dos Extremos" (Eric Hobsbawn), que disseca uma "breve história do século XX" [8], Castells lança um olhar sobre os espaços e tempos do planeta, na época da chamada "globalização". O esforço de abranger o particular e o geral gera um tipo de vertigem pelo excesso e naturalmente nos apresenta elementos valiosos para uma compreensão do novo formato de sociedade e cultura que se configura na aurora do século XXI. No que diz respeito à comunicação e à sua contextualização no âmbito brasileiro, Castells nos parece pertinente ao propor uma reflexão acerca da formação de redes diversas que extrapolam o plano da informatização social. No primeiro volume, "A Sociedade em Rede", o autor aponta para os aspectos de inventividade e criatividade típicos dos californianos (e nos permitiriamos aqui intervir relembrando o estilo inventivo dos brasileiros), que, com ousadia, de maneira "anárquica" e inteligente, deslocaram as experiências informacionais dos meios acadêmicos e militares atualizando a sua forma e sentido no contexto das práticas populares cotidianas através do aperfeiçoamento dos PCs (os micro computadores pessoais). No segundo volume, "O Poder da Identidade", Castells investiga a formação de redes identitárias, perseguindo os rastros dos movimentos religiosos, gays, feministas e ecológicos e mostra como estas redes interagem às vezes de maneira pacífica e outras vezes de maneira conflitiva no contexto da sociedade global. Então, na esfera da comunicação planetária os individuos e grupos se conjugam por meio das redes de identidade, cujas projeções se fazem sentir fortemente na cartografia recente da sociedade em rede. No terceiro volume, "Fim de Milênio", Castells analiza os novos fenômenos derivados da globalização econômica e informacional. Nesta direção observa o colapso da ex-União Soviética, o surgimento do "Quarto Mundo" minado pelos buracos negros do capitalismo informacional, pobreza e exclusão social e o faz examinando a situação da África e os bolsões de pobreza da América. No que respeita especificamente à América Latina, o autor estuda "a conexão 
perversa formada pela economia do crime global" e sua performance sob a égide do narcotráfico.

Manuel Castells nos fornece elementos para examinarmos as culturas híbridas e sua configuração no plano das novas redes de informação. São pistas que nos parecem seguras, sem dúvida. Entretanto, paira a impressão de que precisariamos recorrer a outras fontes no sentido de interpretar rigorosamente as particularidades das conexões que se fazem no conjunto de diferentes redes constituintes da realidade brasileira. Então é preciso atentar para o fato de que a obra de Castells, em sua vasta erudição, não se prestaria a uma aplicabilidade. Ela funcionaria antes como um pano de fundo, como um trabalho de fôlego que nos instiga reflexões relevantes para repensarmos a natureza do nosso hibridismo cultural e nossas interfaces econômicas, sociais, políticas e comunicacionais.

\section{4) Atualização crítica no carnaval da globalização}

Un dos autores mais importantes na área de comunicação, Armand Mattelart, interessa-nos particularmente pela sua afinidade com os temas relativos à comunicação na América Latina e particularmente o Brasil. Enriquecendo a linha de pesquisa voltada para os estudos de Fiç̧ão Seriada Televisiva, Mattelart contribuiu de maneira marcante com a publicação "O carnaval das imagens, a ficção na TV", em que trata das telenovelas e da realidade brasileira. Tendo se dedicado às pesquisas de História da Cultura e da Comunicação, este professor belga produziu obras de cunho crítico e se caracteriza pela conjunção de coletas empíricas e discussões teóricas de fôlego, como atestam diversos títulos, desde "Para ler o Pato Donald" e "Cultura versus Democracia" até "Comunicação Mundo", "A invenção da Comunicação", "História das Teorias da Comunicação" e "A Globalização da Comunicação". Dentre as especificidades dos textos de Mattelart ressalta o cuidado em decifrar a história das estratégias, das técnicas e das linguagens, mostrando os encadeamentos ideológicos, os interesses em jogo que nos permitem enxergar as formas de saber e de poder subjacentes às diferentes modalidades sócio-comunicativas.

No que respeita ao problema da cultura das redes, em "História da Sociedade da Informação" (2001) Mattelart deixa claro que ela traduz o projeto politico de uma minoria dominante, construído exatamente sobre o mito de que a maioria virá a ser contemplada na sociedade da informação. Numa apresentação brilhante escrita por Marcos Marcionilo, podemos ler que, para Mattelart, "vende-se a idéia de que a grande rede mundial reconstruirá em escala global as condições da agora ateniense". Mattelart se mostra cético ante os discursos da dita sociedade global. Para ele isto representa uma "aposta geopolítica" e uma nova forma de hegemonia. "A ideologia da sociedade global da informação é a do mercado, faz parte da reconstrução 
neoliberal do mundo. Há o desígnio dos países dominantes de trazer todas as sociedades à democracia do mercado, que está por trás dos sistemas de inteligência global, de captação de informações que permita vencer os rivais e antecipar os movimentos das grandes organizações da sociedade civil que possam obstacular os desígnios mercadológicos. A liberdade de expressão comercial tem, nesse quadro, toda prioridade sobre a liberdade de expressão dos cidadãos" [-].

Como em seus outros livros, aqui particularmente pensamos em "A Globalização da Comunicação" (1996), Mattelart se coloca de maneira severa em "História da sociedade da informação". Todavia, o autor não recusa, nem se opõe ao avanço dos sistemas de comunicação mundial, ele reconhece que tais sistemas podem gerar níveis de desenvolvimento. Para ele é preciso se manter atento ao sentido dos conceitos de liberdade e democracia. O determinismo técnicosocial não pode dispensar um projeto social. É preciso resguardar a memória. É preciso desconfiar de que o acesso via Internet ao saber universal resolveria o problema da fratura digital e da fratura social. Convém atentar para a concep̧̧ão difusionista de desenvolvimento e discutir o que importa, ou seja: como conceber e colocar em ação outros modelos de desenvolvimento. O mesmo equivale para a noção de progresso e de modernização. Face à ditadura do tempo curto e da velocidade, Mattelart instiga a repensarmos sobre a falta de curiosidade intelectual. Convém oporse ao darwinismo informacional por meio de uma concepção dos novos dispositivos técnicos trabalhados pelas forças criadoras das ciências das artes e das inovações sociais. Refletir sobre os múltiplos entrecruzamentos das mediações sociais, culturais, educativas pelos quais se constroem os usos do mundo digital e que estão na origem da própria vida democrática. Opor-se ao fetichismo da velocidade neofordista por meio de outras relações com o tempo (Mattelart: 2002, p. 174).

\section{5) Culturas híbridas na era da informação}

Dentre as influências marcantes no campo dos estudos de comunicação norteados pela linha de pesquisa voltada para o enfoque das novas tecnologias da informação e da comunicação encontramos em Adriano Rodrigues a expressão de um argumento privilegiado. Dotado de um raciocínio meticuloso e sistemático, armado de um arsenal teórico-conceitual sólido que se apóia nos clássicos da filosofia, sociologia, antropologia, linguística, Rodrigues representa um filão de pensamento que tem conferido rigor $\mathrm{e}$ autonomia ao campo interdisciplinar das ciências da comunicação. No que tange ao eixo temático que privilegiamos sob ó signo da comunicação, cultura e sociedade, encontramos no seu livro "Comunicação e Cultura - a experiência cultural na era da informação" (1994) uma ferramenta privilegiada para a construção de um argumento consistente. 
Adriano Rodrigues se pergunta sobre as transformações que se operam na nossa experiência cultural, numa época em que as fronteiras da informação se sobrepõem aos quadros das solidariedades tradicionais e da racionalidade moderna. Através de uma teoria pragmática da experiência e da abordagem dos atuais dispositivos mediáticos da informação, o livro "Comunicação e Cultura" tenta entender as transformações da nossa experiência individual e coletiva. Rodrigues parte do pressuposto que a queda dos muros que delimitavam as culturas e as nações não equivale necessariamente a uma planetarização da cultura. Novas fronteiras culturais fazem ressurgir, ainda que de maneira por vezes violenta, fluida e transversal, arcaicas divisões e formas de sociabilidade.

Vindo de encontro às nossas indagações sobre as culturas híbridas no contexto do ciberespaço, o pensador percorre diversos campos dos saberes procurando vislumbrar as relações entre as redes de informação e os processos de comunicação. Assim desmistifica as falsas antinomias entre a comunicação e a racionalidade moderna. Apoiando-se em Kant, Weber, Durkheim, entre outros, Rodrigues contextualiza a categoria de "experiência" nos quadros da tradição, da modernidade e da pós-modernidade, observando as dimensões do mito, memória, técnica, política, ciência, ética e estética.

Com base nas Teorias da Significação Adriano Rodrigues percorre os domínios da hermenêutica, da semiologia e da semiótica, chegando a nos propor um exame das modulações recentes do que ele chama de "comunicação reticular", em referência à comunicabilidade propiciada pelas redes e telas.

Apoiando-se na pragmática da comunicação, persegue os termos de uma teoria da enunciação e assim abre caminho para uma reflexão sobre os atos de linguagens que permitem os processos de interatividade. Das formas de legitimidade e dos modos de competência comunicativa, o filósofo propõe um exame das tecnologias da informação, observando a sua lógica reticular, a natureza cultural e política do tipo de racionalidade subjacente à "nova comunicação". De maneira lúcida, discute em que medida as NTC implicam em oportunidade ou morte das culturas tradicionais. Verifica os tipos de anulação das distâncias e suas conseqüências, as especificidades da esfera da tecnicidade, os dispositivos e as funções simbólicas resultantes deste tipo de comunicação.

Adriano Rodrigues realiza uma abstração teórica bastante complexa que exige um maior esforço da parte de quem se predispuser a aplicá-la a alguns setores específicos; entretanto, trata-se de um arsenal de fôlego que pode vir a elucidar várias arestas num exame particular das culturas híbridas e suas interfaces nos tempos da cibercultura.

\section{6) Geopolítica do ciberespaço pelo olhar de Milton Santos}


Temos buscado desenhar um campo possível de descrição de uma epistemologia da cibercultura. Mas antes de tudo a nossa preocupação consiste em examinar de que maneira podemos adequar uma aproximação entre a experiência cultural na era da informação (nos termos de Adriano Rodrigues) e o contexto de hibridismo cultural característico da experiência brasileira, marcada por sérios contrastes socioeconômicos, políticos e culturais. Nessa direção encontramos os discursos e argumentações de Milton Santos, que partindo da geografia e suas interfaces com o domínio das humanidades - nos traz instigantes insights apoiando-se numa teoria crítica da globalização. Em sua vasta obra acadêmica, encontramos uma compilação de textos ensaísticos reunidos sob a sigla "Técnica, Espaço, Tempo Globalização e meio técnico-científico informacional" (1994) cuja ressonância repercute favoravelmente em nossas indagações sobre as formas culturais contemporâneas e as novas tecnologias da informação e da comunicação.

Como podemos depreender, Milton Santos se ocupa da globalização, mas este processo nada mais é do que o conjunto de técnicas e métodos econômicos, políticos, técnicos e mercadológicos que tendem a uniformizar as práticas individuais e coletivas inserindo-as no novo estágio do capitalismo global ou do neoliberalismo. Entendendo que a sua forma mais completa se evidencia por meio dos novos aparatos tecnológicos da informatização, recorremos a Santos recuperando algumas de suas idéias centrais, contidas no trabalho "Técnica, Espaço, Tempo". A primeira consiste em considerar "o 170 presente período histórico como um sistema temporal coerente, cuja explicação exige que sejam levadas em conta as caracteristicas atuais dos sistemas técnicos e as suas relações com a realização histórica". Santos enfatiza a idéia de que "a técnica está longe de ser uma explicação da história, mas ela constitui uma condição fundamental" (Santos: 1994, p. 10). A segunda idéia de Milton Santos que nos parece pertinente é a de que "no presente período histórico, o espaço geográfico pode ser considerado como um "meio técnicocientífico"(Ibidem, p.10).

Dito isso, caberia aqui enunciar os termos que expressam os fragmentos da fala (escrita) do geógrafo, enquanto ferramentas que nos permitiriam repensar as bases epistêmicas do nosso argumento voltado para entender a cibercultura no contexto das culturas híbridas, considerando principalmente o caso do nordeste brasileiro.

A designação de "culturas híbridas", expressão feliz de Nestor Garcia Canclini [-], não pode servir para mascarar os abismos sócio-culturais, econômicos e políticos. Interessa-nos ilustrar no momento (com o apoio de Milton Santos) o modo como se imbricam as instâncias da técnica e da história num dado ambiente geoeconômico e geopolítico. $\mathrm{E}$, no caso brasileiro, isto aparece de modo bem evidente por meio dos terríveis contrastes em que a aproximação cruel entre os shopping-centers e as favelas, internautas e 
analfabetos, tecnocratas e traficantes repartem os mesmos espaços, demonstrando modos de saber, dizer, poder e fazer bem distintos. Ou seja, os meios técnico-cientificos de que dispõem e dos quais se utilizam em suas interações, diferenças e conjunções cotidianas expressam formas diversas num mesmo processo histórico. O desafio que se apresenta é repensar e intervir em novos modos balanceados entre os niveis históricos e tecnológicos, impulsionando modalidades emergentes de informação, educação, comunicabilidade e sociabilidade, gerando formas de participação e de inserção sócio-política e cultural. É neste sentido que caberia examinarmos a fundo a forma e o sentido das culturas híbridas e suas interfaces com as tecnologias informacionais.

\section{7) O pulsar da cultura comunicacional}

Reterritorializando a nossa argumentação acerca das tecnologias da informação e da comunicação, encontramos um arsenal de textos, frutos de pesquisas em diversos niveis de abrangência que expressam a maturidade de um Grupo de Pesquisa resultante dos estudos avançados realizados na USP, a partir dos anos 80, sob a coordenação de Ciro Marcondes Filho. Trata-se de uma experiência pioneira que passou por vários estágios evolutivos, fomentando eixos temáticos, linhas de pesquisa e áreas de concentração em torno do tema Novas Tecnologias da Comunicação. Na realidade, sob o signo "Coletivo NTC", inscreve-se a "reunião de pensadores, pesquisadores e criticos das novas tecnologias de comunicação, com sede na Escola de Comunicação e Artes da USP, buscando por meio da atuação em estudos culturais a intersecção de diferentes disciplinas visando a construção de um paradigma renovado para as Ciências do Homem no século 21 ".

Este Grupo tem engendrado diversas publicações relevantes em nosso campo da comunicação, dentre os quais destacariamos a obra coletiva "PensarPulsar: cultura comunicacional, tecnologias, velocidade" (organizada por Marcondes Filho, 1996). Ainda sob a direção de Marcondes Filho, sublinhamos a revista Attrator estranho (surgida em 1992), contendo uma diversidade de textos registrando discussões acerca das NTC.

O livro "Pensar-Pulsar", que resume grande parte das discussões do GT, parece-nos oportuno para atualizarmos a nossa investigação das Culturas Híbridas e Cibercultura e, aqui, enumeraríamos os títulos dos capítulos a fim de organizar um certa convergência dos temas pertinentes a nossa análise. "O homem na era tecnológica", "Linguagem, Comunicação", "Social, sociabilidade, massas", "O mal-estar na cultura", "Espaço, território, espaço virtual", "Estado, poder, política", "A violência", "Máquinas e racionalidade técnica", "Tempo, história, memória", "Fantasia, estética, nova sensibilidade", "Morte, retorno, negação da morte", "Razão, saber, interpretação" nos permitem vislumbrar a grau de abrangência dos estudos avançados que 
terminaram engendrando o vasto material constituído pelo livro "PensarPulsar". Interessa-nos aqui registrar este momento inaugural de um campo de pesquisa, que na realidade inicia o que Marcondes Filho nomeia por "Nova Teoria da Comunicação".

\section{8) As estruturas antropológicas da cibercultura (André Lemos)}

Na década de 90 o tema da cibercultura já tinha se tornado um assunto up to date no debate acadêmico e já fazia parte das atividades curriculares nas faculdades de comunicação do Brasil. Uma perspectiva original é esboçada por André Lemos, cuja tese de doutorado em sociologia na Sorbonne, intitulada "As estruturas antropológicas da cibercultura", com orientação de Maffesoli, utiliza as categorias propostas por Gilbert Durand em "As estruturas antropológicas do imaginário", construindo uma abordagem do ciberespaço pelo viés das ciências do imaginário, cujo paradigma é proposto por Bachelard em sua vertente poética. Esta perspectiva considera, sobretudo, a dimensão criativa estimulada pela imaginação criadora $e o$ aspecto performativo das redes interativas.

\section{Bibliografia:}

BAUDRILLARD, J. Tela Total, Mito-ironias da era do virtual e da imagem. Sulina, 1997.

172 BOUGNOUX, Daniel. Introdução às ciências da informação e da comunicação. Vozes, 1994.

CANCLINI, Garcia Néstor. Culturas Hibridas. São Paulo: Editora USP, 1997. CARNEIRO LEÃO, M; TAVARES D'AMARAL, M; SODRÉ, M; DORIA, F.A. A Máquina e seu Avesso. Rio de Janeiro: Francisco Alves, 1987.

CASTELLS, M. A era da informação: Economia, Sociedade e Cultura. vol. 1 A sociedade em rede. Rio de Janeiro: Paz e Terra, 1999; _ vol. 2 O poder da identidade. Rio de Janeiro: Paz e Terra, 1999; Paz e Terra, 1999.

FURTADO, Celso. O capitalismo global. Rio de Janeiro: Paz e Terra, 1998. HOBSBAWN, E. Era dos Extremos. S. Paulo: Companhia das Letras, 1996. IANNI, Octavio. A sociedade global. Rio de Janeiro: Civilização Brasileira, 1997.

Teorias da Globalização. Rio de Janeiro: Civilização Brasileira, 1997. LÉVY, P. Cibercultura. S. Paulo: Ed.34, 1998. O que é o virtual. S.Paulo, Ed. 34, . Tecnologias da inteligência. Ed.34. A inteligência coletiva. S. Paulo: Ed. 34.

MACHADO, J; MARTINS, F. Para Navegar no Século XXI - Tecnologias do Imaginário e Cibercultura. Porto Alegre: Sulina, 2000. 
MARCONDES FILHO, C. Vivências Eletrônicas: Sonhadores e Excluidos. S. Paulo: Edições NTC, 1998; __ Cenários do Novo Mundo. S. Paulo: Edições NTC, 1998.

MARCONDES FILHO, Ciro (org) Pensar Pulsar; Cultura comunicacional, tecnologias, velocidade. S.Paulo: Edições NTC, 1996.

MATTELART, Armand. Comunicação-mundo: história das idéias e das estratégias, Petrópolis: Vozes, 1994; Globalização da comunicação. Loyola; _História da sociedade da informação. Loyola.

PARENTE, A. Imagem Máquina. A era das tecnologias do virtual. S.Paulo: Ed. 34, 1993.

PORTO, S.D. Sexo, Afeto e Era Tecnológica. Brasília: Ed. UnB, 1999.

RODRIGUES, Adriano Duarte. Comunicação e cultura: a experiência cultural na era da informação. Lisboa, Editora Presença, 1994.

SANTOS, M. Técnica, Espaço, Tempo - Globalização e Meio técnicocientifico informacional. S. Paulo: HUCITEC, 1994.

SCHEER, L. La démocratie virtuelle. S.Paulo: Flammarion, 1994.

TRIVINHO, E. Redes, Obliterações no fim de século. S.Paulo: Annablume/ FAPESP, 1998.

VIRÍLIO, Paul. A bomba informática. São Paulo: Estação Liberdade, 1999.

\section{Artigos}

BULIK, Linda. O paradigma da informação da era da globalização. FAMECOS n ${ }^{\circ} 5$.

CASALEGNO, F. Hiperliteratura, soc. hipertextuais. FAMECOS n ${ }^{\circ} 9$.

CASALEGNO, F. Entrevista com Sherry Turkle: Fronteiras do real e do virtual. FAMECOS NO.11, Porto Alegre, Dez./99.

LEMOS, A. Arte eletrônica e cibercultura. Famecos n ${ }^{\circ} 6$.

LÉVY, P. A revolução contemporânea em matéria de comunicação. FAMECOS nº.

MACHADO, J. Tecnologias da crença. FAMECOS n9.

MAFFESOLI, M. Mediações simbólicas. FAMECOS, $\mathrm{n}^{\circ} 8$.

MARQUES DE MELO, J. A produção acadêmica brasileira em comunicação: perspectiva dos Novos Tempos. FAMECOS, no. 11, dezembro/99.

MARTINS, F. Cyberespace, redes e telas. FAMECOS n ${ }^{\circ} 6$.

MARTINS, F. Nietzsche, aurora e crepúsculo do mundo verdadeiro em rede. FAMECOS $n^{\circ} 10$.

PARENTE, A. O hipertextual. FAMECOS $n^{\circ} 10$.

PARENTE, A. A arte do observador. FAMECOS nol1. Dez./99.

PRIMO, A. Seria a multimídia de fato interativa? FAMECOS $n^{\circ} 6$.

PRIMO, A. Interfaces potencial e virtual. FAMECOS n 10.

RUDIGER, F. Discussão sobre o receptor ativo na Esc. de Frankfurt. FAMECOS n ${ }^{\circ} 8$. 
PAIVA, C. Experiência e Comunicabilidade na era do virtual. FAMECOS $\mathrm{n}^{\circ} 10$.

Raizes e antenas do Brasil. Rev. SIGNO ${ }^{\circ} 51997$ UFPB

Walter Benjamin e a Imaginação Cibernética CD ROM INTERCOM99 1999 Universidade Gama Filho - Rio de Janeiro - RJ A globalização e sua projeção nos contextos, Caderno B, Correio da Paraiba27.09.98 04.10 .98

Globalização e Mudanças na Paraíba, Caderno B - Correio da Paraíba Páginas virtuais... um universo exuberante, Caderno B, Correio da Paraíba,15.08.99

SFEZ, L. As tecnologias do espirito. FAMECOS n ${ }^{\circ} 6$. POA/RS

TORRES, A. "L'utopie des autoroutes de l'information" in Revue Manière de Voir $\mathrm{n}^{\circ} 27$, Médias et controle des esprits. Août, 1995. Le Monde Diplomatique. TRIVINHO, E. Epistemologia em ruinas. Revista FAMECOS nº5, mês, POA/ RS, 1996.

\section{Bibliografia de textos disponibilizados na Internet} BACCEGA, Maria Aparecida. Conhecimento e Informação Tecnológica http://www.moderna.com.br/Comunicacao/resultado.htm

BENAKOUCHE, Tamara. Redes técnicas, redes sociais: A pré-história da

174 INTERNET. Brasil. In Revista USP, nº35, set.-nov./1997.

http://www.usp.br/geral/infousp/tamara.htm

http://prossiga.br/bibvirtual

BOLAÑO, César Ricardo Siqueira. Sociedade da informação: reestruturação capitalista e esfera pública local.

http://bocc.ubi.pt/pag/bolano-cesar-sociedade-informacao.html

http://bocc.ubi.pt

CÁDIMA, Francisco Rui. Redes à beira de um ataque de conteúdos.

http://bocc.ubi.pt/pag/cadima-rui-redes-conteudos.html

http://bocc.ubi.pt

CARDOSO, Cláudio. Notas sobre a geografia do ciberespaço. In Pretextos, Ufba, 1997.

http://www.facom.ufba.br/pretextos/claudio3.html

ESTEVES, João Pissarra. Liberdade, Comunicação e moral universal.

http://bocc.ubi.pt/pag/esteves-pissarra-liberdade-moral.html

http://bocc.ubi.pt

ESTEVES, João Pissarra. Niklas Luhmann, Uma apresentação.

http://bocc.ubi.pt/pag/esteves-pissarra-luhmann.html

http://bocc.ubi.pt

ESTEVES, João Pissarra. Opinião e democracia na sociedade da informação. 
http://bocc.ubi.pt/pag/esteves-pissarra-opiniao-publica.html

http://bocc.ubi.pt

FIDALGO, A. Os novos meios de comunicação e o ideal de uma comunidade científica

http://bocc.ubi.pt/pag/fidalgo-biblioteca.html

http://bocc.ubi.pt

FIDALGO, A. A distância como virtude. Considerações sobre ética na comunicação

http://bocc.ubi.pt/pag/fidalgo-distancia.html

http://bocc.ubi.pt

FIDALGO, A. A biblioteca universal na sociedade da informação

http://bocc.ubi.pt/pag/fidalgo-biblioteca.html

http://bocc.ubi.pt

HOLANDA, H.B. A academia entre o global e o local

http://acd.ufri.br/pacc/literaria/index.html

MANTA, André; SENA, L. H. As afinidades virtuais: A sociabilidade no videopapo

http://www.facom.ufba.br/pesg/cyber/videopap.html

PAIVA, Cláudio Cardoso de. Walter Benjamin e a Imaginação Cibernética http://bocc.ubi.pt/pag/cardoso-claudio-paiva-walter-benjamin.html

POA/RS

http://ultra.pucrs.br/famecos/10-6.html

BOCC Portugal

PALACIOS, Marcos. Normalização de documentos on line in PRE-TEXTOS, UFBa

http://www.facom.ufba.br/pretextos/

RODRIGUES, Adriano Duarte. As novas tecnologias da Informação e a Experiência.

http://bocc.ubi.pt/pag/rodrigues-adriano-novas-texcnologias.html

http://bocc.ubi.pt

$O$ problema da técnica e o ciberespaço

http://bocc.ubi.pt/pag/jpserra-problema.html

http://bocc.ubi.pt

TEÓFILO, Fernando. Quando a cultura se rende à tecnologia segundo Neil Postman.

http://bocc.ubi.pt/pag/teofilo-fernando-postaman.htmI

http://bocc.ubi.pt

TEÓFILO, Fernando. Tubérculos, capitalismo, esquizofrenia e a Internet, segundo Deleuze e Guattari.

http://bocc.ubi.pt/pag/teofilo-fernando-tuberculos-internet.html

http://bocc.ubi.pt 
TRIGUEIRO, Osvaldo. Globalização e Identidade Cultural:

http://bocc.ubi.pt/pag/trigueiro-osvaldo-globalizacao-identidade.html

http://bocc.ubi.pt .

Palavras-chave

1. Rede

2. Multimídia

3. Epistemologia 